\title{
Detection and Epidemiology of Plasmid-Mediated AmpC b- Lactamase Producing Escherichia Coli in Two Irish Tertiary Care Hospitals
}

Celine Herra

Technological University Dublin, celine.herra@tudublin.ie

Follow this and additional works at: https://arrow.tudublin.ie/scschbioart

Part of the Medicine and Health Sciences Commons

\section{Recommended Citation}

Herra, C. (2015) Detection and epidemiology of plasmid-mediated AmpC b-lactamase producing Escherichia coli in two Irish tertiary care hospitals. J Global Anti Res. vol. 3, no.4, pp 242-46. doi:10.1016/ j.jgar.2015.06.004

This Article is brought to you for free and open access by the School of Biological Sciences at ARROW@TU Dublin. It has been accepted for inclusion in Articles by an authorized administrator of ARROW@TU Dublin. For more information, please contact arrow.admin@tudublin.ie, aisling.coyne@tudublin.ie,gerard.connolly@tudublin.ie.

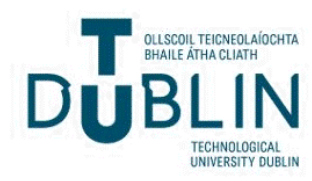




\title{
Detection and epidemiology of plasmid-mediated AmpC $\beta$-lactamase producing Escherichia coli in two Irish tertiary care hospitals
}

\author{
Y.Y. Li ${ }^{\mathrm{a}, 1, *}$, F. Cassidy ${ }^{\mathrm{b}, 1}$, A. Salmon ${ }^{\mathrm{a}}$, D. Keating ${ }^{\mathrm{a}}$, C.M. Herra ${ }^{\mathrm{c}}$, K. Schaffer $^{\mathrm{a}}$ \\ a Department of Microbiology, St Vincent's University Hospital, Dublin 4, Ireland \\ ${ }^{\mathrm{b}}$ Department of Microbiology, Blackrock Clinic, Co. Dublin, Ireland \\ ' School of Biological Sciences, Dublin Institute of Technology, Kevin Street, Dublin 8, Ireland
}

\section{A R T I C L E I N F O}

\section{Article history:}

Received 10 December 2014

Received in revised form 1 May 2015

Accepted 10 June 2015

\section{Keywords:}

Plasmid-mediated AmpC $\beta$-lactamase

Escherichia coli

Pulsed-field gel electrophoresis

Multilocus sequence typing

\begin{abstract}
A B S T R A C T
This study determined the prevalence and distribution of plasmid-mediated AmpC (pAmpC) $\beta$-lactamases in Irish Escherichia coli isolates. Clinical E. coli isolates $(n=95)$ that were intermediate or resistant to cefoxitin and/or flagged by VITEK $^{\circledR} 2$ as potential AmpC-producers underwent confirmation using a MASTDISCS ${ }^{\mathrm{TM}}$ ESBL and AmpC Detection Kit. Multiplex PCR capable of detecting family-specific plasmid $a m p C$ genes was performed to detect the presence of these genes. Five PCRnegative isolates were selected for promoter analysis. PFGE and MLST were performed on E. coli isolates that harboured a plasmid $a m p C$ gene to determine their clonal relatedness. Plasmid $a m p C$ genes were detected in 19\% (18/95) of phenotypic AmpC producing E. coli isolates. The CIT group was the most common plasmid family type $(n=14)$; $\operatorname{DHA}(n=3)$ and $\operatorname{ACC}(n=1)$ groups were also detected. Promoter analysis showed that four isolates had multiple point mutations and one had a $1 \mathrm{bp}$ insertion in the -10 box. PFGE demonstrated a polyclonal pattern for E. coli isolates. Furthermore, with the exception of two isolates with an identical sequence type (ST720), MLST analysis revealed that these isolates were not clonally related. This study revealed that there was a marked prevalence of pAmpC E. coli among phenotypic AmpC producing $E$. coli isolates but no evidence of cross-transmission of a single strain. Establishing the prevalence and clonality of these organisms is important in order to implement evidence-based infection control measures that reduce the spread of pAmpC $\beta$-lactamase resistance in the hospital environment.

(C) 2015 Published by Elsevier Ltd on behalf of International Society for Chemotherapy of Infection and
\end{abstract}

Cancer.

\section{Introduction}

Antibiotic resistance among Enterobacteriaceae is an everincreasing concern both in Ireland and worldwide. Infection with antibiotic-resistant Enterobacteriaceae can lead to treatment failures due to limited antibiotic treatment options as well as posing the risk of cross-infection. AmpC $\beta$-lactamase producing organisms hydrolyse narrow-, broad- and expanded-spectrum cephalosporins and cephamycins (e.g. cefoxitin) and are usually only susceptible to fourth-generation cephalosporins and carbapenems [1]. AmpC $\beta$-lactamase resistance may be conferred through chromosomal or plasmid-mediated origins.

\footnotetext{
* Corresponding author. Tel.: +35312213994.

E-mail address: yuenyil@hotmail.com (Y.Y. Li).

1 These authors contributed equally to this study.
}

The chromosomal ampC gene in Escherichia coli is generally expressed at low levels, not causing clinical resistance, because the promoter is weak and the gene contains a transcriptional attenuator [2]. However, constitutive overexpression of $a m p C$ in $E$. coli can occur due to either the hyperproduction of a chromosomally encoded $a m p C$ gene or by acquisition of a transferable ampC gene on a plasmid [3]. The occurrence of $a m p C$ $\beta$-lactamases on plasmids presents the threat of spreading this resistance mechanism to other organisms within a hospital or geographic region.

Ireland started reporting third-generation cephalosporin sensitivity among E. coli in 2002. Between 2002 and 2010, the proportion of resistant $E$. coli increased from $2.2 \%$ to $7.7 \%$. There is limited information with regard to the prevalence and epidemiology of plasmid-mediated AmpC (pAmpC) $\beta$-lactamases among $E$. coli in Ireland. Roche et al. reported that $3 \%$ of Klebsiella pneumoniae collected prospectively from April 2005 to March 2007 carried 
pAmpC in Ireland [4]. A study undertaken by the UK Antibiotic Resistance Monitoring and Reference Laboratory in 2007 reported a prevalence rate of pAmpC of 49\% (67/135) and 55\% (21/38) among cephalosporin- and cefoxitin-resistant E. coli and Klebsiella spp., respectively [5]. It is important to identify the occurrence of $\mathrm{pAmpC}$ in these organisms in order to implement necessary infection control measures.

The aim of this study was to establish the prevalence and clonality of clinical isolates of $\mathrm{pAmpC}$ producing E. coli in two south Dublin hospitals. E. coli isolates that were intermediate or resistant to cefoxitin and/or were flagged by the VITEK $^{\circledR} 2$ system as potential AmpC-producers underwent a phenotypic test to confirm the production of an AmpC $\beta$-lactamase. Multiplex PCR was subsequently carried out to identify the presence of plasmid ampC genes among isolates that demonstrated an AmpC phenotype. Finally, the genetic relatedness of $\mathrm{pAmpC}$ producing $E$. coli isolates was investigated through pulsed-field gel electrophoresis (PFGE) and multilocus sequence typing (MLST).

\section{Methods}

\subsection{Bacterial strains and antimicrobial susceptibility testing}

A total of 95 non-duplicate AmpC producing E. coli isolates were collected from two hospitals in Dublin (Ireland) from March 2011 to October 2012.

Identification and susceptibility testing were performed by the VITEK $^{\circledR} 2$ Compact (bioMerieux, Marcy-l'Étoile, France) and the results were interpreted according to European Committee on Antimicrobial Susceptibility Testing (EUCAST) clinical breakpoints v.2.0 and EUCAST Expert rules v.1.0 [6]. The advanced expert system (AES) of the VITEK ${ }^{\circledR} 2$ Compact identified the isolates as potential AmpC producers on the basis of an antimicrobial susceptibility pattern that is compatible with an AmpC producing phenotype, i.e. resistance to first- and second-generation cephalosporins, resistance to one or more of the third-generation cephalosporins and/or reduced susceptibility to cefoxitin, and sensitivity to the fourth-generation cephalosporin cefepime.

\subsection{Phenotypic AmpC $\beta$-lactamase detection}

Isolates were confirmed phenotypically as AmpC $\beta$-lactamase producers by the MASTDISCS ${ }^{\mathrm{TM}}$ ESBL and AmpC Detection Kit (MAST Group Ltd., Merseyside, UK). The MASTDISCS ${ }^{\mathrm{TM}}$ kit is an inhibitorbased test that detects the presence of AmpC $\beta$-lactamases and extended-spectrum $\beta$-lactamases (ESBLs). Briefly, a Mueller-Hinton agar plate (L.I.P. Diagnostic Services, Galway, Ireland) was inoculated with a 0.5 McFarland standard suspension of a test isolate. The A (10 $\mu \mathrm{g}$ cefpodoxime), B (10 $\mu \mathrm{g}$ cefpodoxime + the ESBL inhibitor clavulanic acid), $C(10 \mu \mathrm{g}$ cefpodoxime + the AmpC inhibitor cloxacillin) and D (10 $\mu$ g cefpodoxime + ESBL and AmpC inhibitors) disks were applied onto the plate. The zone of inhibition around each disc was measured following $18-24$ h of incubation at $37^{\circ} \mathrm{C}$ in air and was interpreted according to the manufacturer's instructions.

\subsection{Multiplex $P C R$}

Isolates confirmed as AmpC $\beta$-lactamase producers by the phenotypic MASTDISCS ${ }^{\mathrm{TM}}$ ESBL and AmpC Detection Kit were screened for the presence of a plasmid-borne $a m p C$ gene using a multiplex PCR assay developed by Pérez-Pérez and Hanson [7]. This PCR utilises six primer sets to detect the six phylogenetic families of plasmid ampC $\beta$-lactamase genes (i.e. bla $a_{\mathrm{FOX}}, b l a_{\mathrm{CIT}}, b l a_{\mathrm{DHA}}$, $b l a_{\mathrm{EBC}}, b l a_{\mathrm{MOX}}$ and $b l a_{\mathrm{ACC}}$ ) on the basis of amplicon size and was performed as described previously [7]. A representative group of bla $a_{\mathrm{CIT}} \mathrm{PCR}$ products $(n=7)$ were randomly selected for sequencing.
Sequence alignments and analysis were performed using the NCBI BLAST programme (http://www.ncbi.nlm.nih.gov).

\subsection{Promoter analysis}

Five of the multiplex PCR negative isolates were analysed for ampC promoter mutations, which included promoter PCR, sequencing of the products and multiple sequence alignment with the E. coli K12 strain promoter sequence [8].

\subsection{Pulsed-field gel electrophoresis}

Agarose-embedded plugs containing intact bacterial DNA were prepared using a CHEF (Contour-Clamped Homogenous Electric Fields) Mapper Plug Kit (Bio-Rad Laboratories, Hemel Hempstead, UK) according to the manufacturer's instructions. Following overnight digestion of the plugs with $\mathrm{Xbal}$ at $37^{\circ} \mathrm{C}$, PFGE was performed on a CHEF Mapper XA PFGE System (Bio-Rad Laboratories) according to the PulseNet standardised laboratory protocol [9]. The electrophoresis conditions were optimised for separation of the $30-600 \mathrm{~kb}$ fragments in a $1 \%$ agarose gel with $0.5 \times$ TBE [Tris-borate-ethylene diamine tetra-acetic acid (EDTA)] buffer and a voltage of $6 \mathrm{~V} / \mathrm{cm}$ for $19 \mathrm{~h}$, with an initial switch time of $2.2 \mathrm{~s}$ and final switch time of $54.2 \mathrm{~s}$. A dendrogram was constructed using the Dice coefficient with an optimisation of $1 \%$ and a tolerance of $1 \%$ in band position difference (FPQuest ${ }^{\mathrm{TM}}$ Software; Bio-Rad Laboratories). The clonal relationship among isolates was determined according to the criteria of Tenover et al. [10]. Clonal groups were assigned based on a similarity of $\geq 80 \%$ ( $\leq 3$ band difference in restriction profile).

\subsection{Multilocus sequence typing}

Nine $E$. coli isolates harbouring a plasmid $a m p C$ gene were selected for further characterisation through the $E$. coli MLST scheme developed by the Achtman group [11]. The protocol for this typing method, including the PCR primers, PCR components and cycling conditions required, was accessed through the online MLST E. coli database [12]. The PCR products of the seven housekeeping genes on all nine $E$. coli isolates were subsequently purified for sequencing using a QIAquick PCR Purification Kit (QIAGEN, Hilden, Germany). Sanger sequencing was performed by an external laboratory (Source BioScience, LifeSciences, Dublin, Ireland) and the MLST PCR primer pairs were used for the sequencing step. The sequencing data of each isolate were entered into the E. coli MLST online database (http://mlst.ucc.ie/mlst/dbs/Ecoli) to give a distinct allelic number. The alleles for the seven loci were combined to give an allelic profile or sequence type (ST). The STs of each of the nine isolates were collated and compared.

\section{Results}

\subsection{Antimicrobial susceptibility testing and MASTDISCS ${ }^{T M}$}

Ninety-five $E$. coli isolates were identified by the VITEK ${ }^{\circledR}$ 2 system as potential AmpC producers and were phenotypically confirmed for AmpC production using combination disks. One isolate was positive for the coexistence of AmpC and ESBL enzymes. E. coli isolates demonstrated variable resistance to the third-generation cephalosporins, with some isolates only resistant to one of either cefotaxime or ceftazidime or sensitive to both. Isolates that were positive for a plasmid $a m p C$ gene generally had higher minimum inhibitory concentrations (MICs) against the third-generation cephalosporins than chromosomally mediated AmpC producing isolates (Table 1). A total of $94 \%$ (17/18) and 83\% $(15 / 18)$ of $\mathrm{pAmpC}$ isolates were resistant to ceftazidime and 
Table 1

Minimum inhibitory concentrations (MICs) (in mg/L) of Escherichia coli isolates with an AmpC phenotype.

\begin{tabular}{llllll}
\hline \multirow{2}{*}{ Antibiotic } & \multicolumn{2}{l}{ pAmpC $(n=18)$} & & \multicolumn{2}{c}{ Chromosomal AmpC $(n=77)$} \\
\cline { 2 - 3 } \cline { 5 - 6 } & Mode MIC & MIC range & & Mode MIC & MIC range \\
\hline AMP & $\geq 32$ & $\geq 32$ & & $\geq 32$ & $\geq 32$ \\
CXM & $\geq 64$ & 16 to $\geq 64$ & & 16 & 4 to $\geq 64$ \\
CTX & 16 & $\leq 1$ to $\geq 64$ & & $\leq 1$ & $\leq 1$ to 16 \\
CAZ & 8 & $\leq 1$ to $\geq 64$ & & $\leq 1$ & $\leq 1$ to $\geq 64$ \\
FEP & $\leq 1$ & $\leq 1-2$ & & $\leq 1$ & $\leq 1$ \\
FOX & $\geq 64$ & 8 to $\geq 64$ & & 16 & $\leq 4$ to $\geq 64$ \\
MEM & $\leq 0.25$ & $\leq 0.25$ & & $\leq 0.25$ & $\leq 0.25$ \\
ETP & $\leq 0.5$ & $\leq 0.5-1$ & & $\leq 0.5$ & $\leq 0.5$ \\
GEN & $\leq 1$ & $\leq 1$ to $\geq 16$ & & $\geq 1$ & 0.25 to $\leq 16$ \\
CIP & $\leq 0.25$ & $\leq 0.25$ to $\geq 4$ & & $\leq 0.25$ & $\leq 0.25$ to $\geq 4$ \\
\hline
\end{tabular}

pAmpC, plasmid-mediated AmpC; AMP, ampicillin; CXM, cefuroxime; CTX, cefotaxime; CAZ, ceftazidime; FEP, cefepime; FOX, cefoxitin; MEM, meropenem; ETP, ertapenem; GEN, gentamicin; CIP, ciprofloxacin.

cefotaxime, respectively. In contrast, chromosomally mediated AmpC producing isolates were more sensitive, with only $12 \%$ (9/ 77) resistant to ceftazidime and $14 \%(11 / 77)$ resistant to cefotaxime. With the exception of one isolate (E25), AmpCproducing $E$. coli isolates in this study were resistant to cefoxitin. Most isolates $(n=94)$ were sensitive to the fourth-generation cephalosporin cefepime, except for one isolate (E23) that was also non-susceptible to ertapenem. All 95 isolates were sensitive to meropenem. In addition, many isolates demonstrated multiresistance; 16 isolates displayed resistance to the aminoglycoside gentamicin and 31 isolates were resistant to the fluoroquinolone ciprofloxacin.

\subsection{AmpC multiplex PCR}

Of the 95 isolates that were screened for the presence of a plasmid ampC $\beta$-lactamase gene by multiplex PCR, 18 isolates (19\%) were pAmpC positive. The predominant gene was bla $a_{\mathrm{CIT}}$, detected in $14 \mathrm{E}$. coli isolates (Table 2 ). Nucleotide sequencing of a representative group of these isolates $(n=7)$ revealed $100 \%$ concordance with the $b l a_{\mathrm{CMY}-2}$ gene sequence (GenBank accession no. HQ680723). Other PAmpC genes identified were $b l a_{\mathrm{DHA}}(n=3)$ and $\operatorname{bla}_{\mathrm{ACC}}(n=1)$. The majority of phenotypic AmpC producing $E$. coli isolates were negative for a $\mathrm{pAmpC}$ gene, which suggests that the presence of AmpC could be due to either hyperproduction of chromosomal AmpC or acquisition of novel plasmids that were not detected by the multiplex PCR in this study.

\subsection{Promoter analysis}

Five of the multiplex PCR negative isolates were analysed for ampC promoter mutations. Four of them had multiple point mutations in the promoter region and one had a 1-bp insertion in the -10 box compared with E. coli $\mathrm{K} 12$ (Table 3 ). The predominant point mutation was at +58 , followed by the -35 box.

\subsection{Isolates with plasmid-mediated AmpC are genetically unrelated}

The $18 \mathrm{E}$. coli isolates harbouring plasmid $a m p C$ genes were not clonally related by PFGE analysis and revealed $<50 \%$ sequence homology. Furthermore, a representative group of nine pAmpC positive E. coli isolates were typed by MLST. With the exception of two isolates (isolates 90 and 91), which were ST720, MLST analysis revealed that these isolates were unrelated (Table 2). Apart from ST493 and ST3672, all of the MLST types have been previously detected both in humans and livestock in Europe [12]. ST493 has been isolated from humans in Japan and ST3672 from wild animals in China [12].

\section{Discussion}

Antimicrobial resistance among Enterobacteriaceae is fast becoming a worldwide public health concern, and AmpC $\beta$ lactamases are an emerging group of antimicrobial resistance determinants [13]. The occurrence of $a m p C$ genes on plasmids presents a great challenge to infection control because plasmidmediated genes can spread to other organisms within a hospital or geographic region. The lack of a widely accepted phenotypic AmpC $\beta$-lactamase detection method greatly hinders accurate detection and surveillance of AmpC producers and hence the ability to limit the spread of $\mathrm{pAmpC}$ resistance. This study was designed to determine the prevalence and clonality of $\mathrm{pAmpC}$ producing $E$. coli in two Dublin hospitals.

Table 2

Antimicrobial susceptibility and sequence types (STs) by multilocus sequence typing of plasmid-mediated AmpC-producing Escherichia coli ( $n=18$ ).

\begin{tabular}{|c|c|c|c|c|c|c|c|c|c|c|c|c|}
\hline \multirow[t]{2}{*}{ Isolate } & \multicolumn{10}{|c|}{ MIC (mg/L) } & \multirow{2}{*}{$\begin{array}{l}\text { AmpC multiplex } \\
\text { PCR (plasmid } \\
\text { bla }_{\text {AmpC }}\end{array}$} & \multirow[t]{2}{*}{ ST } \\
\hline & AMP & CXM & CAZ & CTX & FOX & FEP & MER & ETP & GEN & CIP & & \\
\hline E05 & $>32$ & 16 & 4 & 8 & $>64$ & $\leq 1$ & $\leq 0.25$ & $\leq 0.5$ & $>16$ & $>4$ & CIT & NT \\
\hline E16 & $>32$ & $>64$ & $>64$ & $>64$ & 32 & $\leq 1$ & $\leq 0.25$ & $\leq 0.5$ & $>16$ & $>4$ & CIT & NT \\
\hline E18 & $>32$ & 16 & 4 & 4 & 32 & $\leq 1$ & $\leq 0.25$ & $\leq 0.5$ & $\leq 1$ & $>4$ & CIT & NT \\
\hline E19 & $>32$ & $>64$ & $>64$ & $>64$ & $>64$ & $\leq 1$ & $\leq 0.25$ & $\leq 0.5$ & $\leq 1$ & 0.5 & CIT & NT \\
\hline E23 & $>32$ & $>64$ & $>64$ & $>64$ & $>64$ & 2 & $\leq 0.25$ & 1 & $\leq 1$ & $\leq 0.25$ & CIT & NT \\
\hline E25 & $>32$ & 32 & 32 & 8 & 8 & $\leq 1$ & $\leq 0.25$ & $\leq 0.5$ & $\leq 1$ & $>4$ & ACC & NT \\
\hline E27 & $>32$ & 16 & 4 & $\leq 1$ & $>64$ & $\leq 1$ & $\leq 0.25$ & $\leq 0.5$ & $>16$ & $\leq 0.25$ & DHA & NT \\
\hline E35 & $>32$ & $>64$ & $>64$ & 16 & $>64$ & $\leq 1$ & $\leq 0.25$ & $\leq 0.5$ & $>16$ & $>4$ & CIT & NT \\
\hline E53 & $>32$ & $>64$ & $>64$ & 32 & $>64$ & $\leq 1$ & $\leq 0.25$ & $\leq 0.5$ & $\leq 1$ & $\leq 0.25$ & CIT & NT \\
\hline E90 & $>32$ & $>64$ & $>64$ & 16 & $>64$ & $\leq 1$ & $\leq 0.25$ & $\leq 0.5$ & $\leq 1$ & $\leq 0.25$ & CIT & ST720 (35-3-58-6-5-16-4) \\
\hline E91 & $>32$ & $>64$ & $\leq 1$ & $\leq 1$ & $>64$ & $\leq 1$ & $\leq 0.25$ & $\leq 0.5$ & 8 & $\leq 0.25$ & CIT & ST720 (35-3-58-6-5-16-4) \\
\hline E113 & $>32$ & $>64$ & 4 & 4 & $>64$ & $\leq 1$ & $\leq 0.25$ & $\leq 0.5$ & $\leq 1$ & $>4$ & DHA & ST38 (4-26-2-25-5-5-19) \\
\hline E130 & $>32$ & 32 & 16 & 8 & $>64$ & $\leq 1$ & $\leq 0.25$ & $\leq 0.5$ & $\leq 1$ & $\leq 0.25$ & CIT & ST3672 (76-13-190-13-17-30-25) \\
\hline B6 & $>32$ & 16 & 16 & 4 & $>64$ & $\leq 1$ & $\leq 0.25$ & $\leq 0.5$ & $\leq 1$ & $>4$ & CIT & ST10 (10-11-4-8-8-8-2) \\
\hline B7 & $>32$ & $>64$ & 16 & $\leq 1$ & $>64$ & $\leq 1$ & $\leq 0.25$ & $\leq 0.5$ & $>16$ & $\leq 0.25$ & DHA & ST493 (40-13-9-13-16-10-9) \\
\hline B10 & $>32$ & 16 & 16 & 8 & $>64$ & $\leq 1$ & $\leq 0.25$ & $\leq 0.5$ & $\leq 1$ & $\leq 0.25$ & CIT & ST92 (40-14-19-36-23-11-10) \\
\hline B12 & $>32$ & 32 & 16 & 8 & $>64$ & $\leq 1$ & $\leq 0.25$ & $\leq 0.5$ & $\leq 1$ & $\leq 0.25$ & CIT & ST906 (6-4-3-16-11-8-6) \\
\hline B18 & $>32$ & $>64$ & 16 & 8 & $>64$ & $\leq 1$ & $\leq 0.25$ & $\leq 0.5$ & $\leq 1$ & $>4$ & CIT & ST354 (85-88-78-29-59-58-62) \\
\hline
\end{tabular}

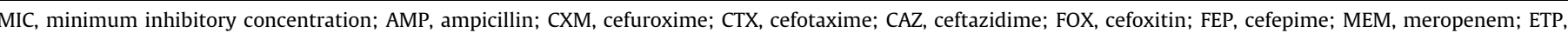
ertapenem; GEN, gentamicin; CIP, ciprofloxacin; NT, not tested. 
Table 3

Mutations identified in the Escherichia coli ampC promoter region.

\begin{tabular}{ll}
\hline $\begin{array}{l}\text { Isolate } \\
\text { number }\end{array}$ & Mutations $^{\mathrm{a}}$ \\
\hline E7 & $-88(\mathrm{C} \rightarrow \mathrm{T}),-82(\mathrm{~A} \rightarrow \mathrm{G}),-18(\mathrm{G} \rightarrow \mathrm{A}),-1(\mathrm{C} \rightarrow \mathrm{T}),+58(\mathrm{C} \rightarrow \mathrm{T})$ \\
E10 & -35 box $(\mathrm{T} \rightarrow \mathrm{A}),+58(\mathrm{G} \rightarrow \mathrm{T}),+63(\mathrm{~T} \rightarrow \mathrm{C})$ \\
E31 & $+70(\mathrm{C} \rightarrow \mathrm{T})$ \\
& Attenuator: $+21(\mathrm{C} \rightarrow \mathrm{T}),+25(\mathrm{~T} \rightarrow \mathrm{G}),+26(\mathrm{~A} \rightarrow \mathrm{T}),+31(\mathrm{G} \rightarrow \mathrm{A})$ \\
E36 & -35 box $(\mathrm{T} \rightarrow \mathrm{A}),+58(\mathrm{C} \rightarrow \mathrm{T}),+63(\mathrm{~T} \rightarrow \mathrm{C})$ \\
E46 & 1 bp $(\mathrm{T})$ insertion in the -10 box \\
\hline a
\end{tabular}

a Compared with E. coli $\mathrm{K} 12$.

A total of $95 \mathrm{E}$. coli clinical isolates phenotypically identified as AmpC $\beta$-lactamase producers by VITEK ${ }^{\circledR} 2$ and combination disks were included in this study. Whilst the majority of them were identified as possible chromosomal AmpC hyperproducers $(n=77)$, a total of 18 isolates $(19 \%)$ were pAmpC producers. This is compared with a study undertaken by the UK antimicrobial reference laboratory including Irish isolates that reported a prevalence rate of pAmpC of 49\% (67/135) among cephalosporin-resistant $E$. coli spp. [5]. The higher prevalence rate detected in the UK study could potentially be explained by the fact that microbiology laboratories would only send the most resistant isolates for further analysis to reference laboratories, whereas in the current study serial clinical isolates exhibiting an AmpC phenotype were collected. Other studies carried out in hospital laboratories and similar in design to this study have revealed various prevalence rates. For example, a study from Denmark reported a similar prevalence to our data, in which $17 \%$ (4/24) of $E$. coli carried a plasmid $a m p C$ gene [14], whilst a study in Switzerland reported a higher prevalence at $38 \%$ (8/21) [15].

The predominant $a m p C$ gene detected in this study was bla $a_{\mathrm{CIT}}$, identified in $14 \mathrm{E}$. coli isolates. Nucleotide sequencing of a representative group of these isolates $(n=7)$ revealed the $b a_{\mathrm{CMY}-2}$ gene. This observation is consistent with many other studies worldwide in which CMY-2 is the most commonly acquired plasmid and widely geographically distributed AmpC enzyme [5,15-22].

In addition, $b l a_{\mathrm{DHA}}(n=3)$ and bla $_{\mathrm{ACC}}(n=1)$ were also detected. The CIT, DHA and ACC AmpC enzymes have been previously identified among $E$. coli and $K$. pneumoniae isolates in Ireland $[4,5]$. The isolate (E25) that harboured a bla $a_{\mathrm{AcC}}$ gene in this study was susceptible to cefoxitin, which correlates with many studies showing that isolates with ACC enzyme are sensitive to cefoxitin $[4,23]$. It is important to consider that the use of cefoxitin resistance as a screening marker may be compromised by isolates producing plasmid-encoded ACC AmpC $\beta$-lactamases that are sensitive to cefoxitin.

This study revealed that $\mathrm{pAmpC}$ producing $E$. coli isolates displayed higher MICs to the third-generation cephalosporins and cefoxitin than chromosomal AmpC hyperproducing E. coli (Table 1). Concomitant resistance to cefotaxime, ceftazidime and cefoxitin in phenotypic AmpC-producing E. coli isolates was suggestive of $\mathrm{pAmpC}$ production. Hence, whilst routine molecular testing for pAmpC in E. coli is currently unavailable in Ireland, the susceptibility profile of a phenotypically confirmed AmpC producing $E$. coli may help to distinguish between $\mathrm{pAmpC}$ production and chromosomal AmpC hyperproduction.

Co-resistance to other antimicrobials was frequently observed among these isolates. For example, ciprofloxacin resistance was observed in 33\% (31/95) of AmpC producers in this study. A rising trend of fluoroquinolone resistance among AmpC producing E. coli has been reported by Simner et al. [3].

The coexistence of multiple resistance mechanisms in an organism is a concern as multidrug resistance can severely limit therapeutic options. In this study, co-production of AmpC and ESBL was detected in one isolate. Continuous resistance surveillance and the implementation of infection control measures are important to reduce the spread of multidrug-resistant organisms. Five of the multiplex PCR negative isolates were analysed for $a m p C$ promoter mutations and the results suggested that they are common mutations as they were also identified by Haldorsen et al., who reported three different mechanisms for increased expression of chromosomal $a m p C$ genes including multiple point mutations (positions $-1,-18,-42,-82,-88$ and +58 ) and single nucleotide or insertion sequence (IS) element insertions between the -35 and -10 boxes [16]. Further work is required to investigate the role of $a m p C$ promoter mutations in AmpC hyperproduction.

Detection of a plasmid $a m p C$ gene in an AmpC producing organism provides a valuable insight into the resistance mechanism of an isolate and the potential for this resistance to spread. It is equally important to understand whether antimicrobial resistance is due to the transmission of resistance genes from organism to organism or through the transmission of a single resistant strain. Molecular typing by PFGE and MLST was performed in this study to investigate whether $\mathrm{pAmpC}$ isolates were clonally related and hence the result of the spread of a single strain. PFGE showed that the pAmpC producers $(n=18)$ represented different DNA restriction patterns with $<50 \%$ fragments sharing homology. These results suggest that the incidence of transferable AmpC in E. coli was the result of a mobile element rather than the spread of a single clone.

MLST was carried out on a representative group $(n=9)$ of pAmpC E. coli isolates in this study. MLST was performed due to the worldwide clonal dissemination of $E$. coli ST131 and recent detection of pAmpC $\beta$-lactamases among E. coli ST131 [24,25]. Among the nine selected E. coli isolates, MLST identified eight different STs. The pandemic E. coli clone ST131 was not detected in this study. Two isolates (isolates E90 and E91) had the same allelic profiles and therefore the same ST (ST720). These two isolates only displayed $40 \%$ similarity by PFGE, highlighting that MLST has a lower discriminating ability compared with PFGE, as reported in previous studies [26-28]. The remaining seven isolates had different individual allelic profiles and therefore different STs. The ST38 isolate in this study (isolate E113) carried a bla $a_{\text {DHA }}$ plasmid $a m p C$ gene. However, in two separate studies, pAmpC E. coli isolates related to the sequence type complex (STC) 38 instead harboured a bla $a_{\mathrm{CIT}}$ plasmid $a m p C$ gene $[24,25]$. This illustrates how plasmids can spread among isolates and also that this globally distributed $E$. coli strain can acquire different plasmid ampC genes. Other strains identified in this study (ST92, ST493, ST720, ST906 and ST3672) have not been previously reported among $\mathrm{pAmpC}$ producing $E$. coli in the literature and could indicate that there has been further spread of plasmid $a m p C$ genes among E. coli strains.

In conclusion, this study revealed that there was a prevalence of $19 \%$ of pAmpC producing E. coli among isolates displaying an AmpC phenotype in two Dublin hospitals. The fact that the isolates investigated by PFGE and MLST were not clonally related demonstrates that $\mathrm{pAmpC}$ resistance was due to the transfer of plasmids among isolates rather than the spread of a single organism. As both hospitals do not routinely isolate patients harbouring $E$. coli with an AmpC phenotype, the lack of evidence for cross-infection by PFGE was reassuring. These findings emphasise the importance of investigating AmpC $\beta$-lactamases in clinical isolates at a molecular level, although routine molecular testing is currently beyond the scope of Irish diagnostic laboratories. In this way, informed and evidence-based infection control polices can be introduced to reduce the spread of $\mathrm{pAmpC}$ resistance in hospitals and limit the movement of this resistance mechanism. 


\section{Funding}

St Vincent's University Hospital Microbiology Research Fund (Dublin, Ireland).

\section{Competing interests}

None declared.

\section{Ethical approval}

Not required.

\section{Acknowledgments}

The authors gratefully acknowledge the assistance of staff at the two collaborating microbiology laboratories for the collection of isolates.

\section{References}

[1] Thomson KS. Extended-spectrum- $\beta$-lactamase, AmpC, and carbapenemase issues. J Clin Microbiol 2010;48:1019-25.

[2] Jaurin B, Grundström T, Edlund T, Normark S. The E. coli $\beta$-lactamase attenuator mediates growth rate-dependent regulation. Nature 1981;290:221-5.

[3] Simner PJ, Zhanel GG, Pitout J, Tailor F, McCracken M, Mulvey MR, et al. Prevalence and characterization of extended-spectrum $\beta$-lactamase- and AmpC $\beta$-lactamase-producing Escherichia coli: results of the CANWARD 2007-2009 study. Diagn Microbiol Infect Dis 2011;69:326-34.

[4] Roche C, Boo TW, Walsh F, Crowley B. Detection and molecular characterisation of plasmidic AmpC $\beta$-lactamases in Klebsiella pneumoniae isolates from a tertiary-care hospital in Dublin, Ireland. Clin Microbiol Infect 2008;14:616-8.

[5] Woodford N, Reddy S, Fagan EJ, Hill RL, Hopkins KL, Kaufmann ME, et al. Wide geographic spread of diverse acquired AmpC $\beta$-lactamases among Escherichia coli and Klebsiella spp. in the UK and Ireland. J Antimicrob Chemother 2007;59:102-5.

[6] European Committee on Antimicrobial Susceptibility Testing. Breakpoint tables for interpretation of MICs and zone diameters. Version 2.0, 2012. EUCAST; 2012, http://www.eucast.org/ast_of_bacteria/previous_versions_of_documents/ [accessed 08.07.15].

[7] Pérez-Pérez FJ, Hanson ND. Detection of plasmid-mediated AmpC $\beta$-lactamase genes in clinical isolates by using multiplex PCR. J Clin Microbiol 2002;40: 2153-62.

[8] Corvec S, Caroff N, Espaze E, Marraillac J, Reynaud A. -11 Mutation in the ampC promoter increasing resistance to $\beta$-lactams in a clinical Escherichia coli strain. Antimicrob Agents Chemother 2002;46:3265-7.

[9] PulseNet, US Centres for Disease Control and Prevention. Standard operating procedure for PulseNet PFGE of Escherichia coli 0157:H7, Escherichia coli nonO157 (STEC), Salmonella serotypes, Shigella sonnei and Shigella flexneri. CDC; 2009, http://www.cdc.gov/pulsenet/PDF/ecoli-shigella-salmonella-pfgeprotocol-508c.pdf [accessed 18.03.14].

[10] Tenover FC, Arbeit RD, Goering RV, Mickelsen PA, Murray BE, Persing DH, et al. Interpreting chromosomal DNA restriction patterns produced by pulsed-field gel electrophoresis: criteria for bacterial strain typing. J Clin Microbiol 1995; $33: 2233-9$.
[11] Wirth T, Falush D, Lan R, Colles F, Mensa P, Wieler LH, et al. Sex and virulence in Escherichia coli: an evolutionary perspective Mol Microbiol 2006:60:1136-51.

[12] MLST Databases. Escherichia coli MLST database. University College Cork; 2013, http://mlst.ucc.ie/mlst/dbs/Ecoli/documents/primersColi_html [accessed 18.03.14].

[13] Ingram PR, Inglis TJJ, Vanzetti TR, Henderson BA, Harnett GB, Murray RJ Comparison of methods for AmpC $\beta$-lactamase detection in Enterobacteriaceae. J Med Microbiol 2011;60:715-21.

[14] Jørgensen RL, Nielsen JB, Friis-Møller A, Fjeldsøe-Nielsen H, Schønning K. Prevalence and molecular characterization of clinical isolates of Escherichia coli expressing an AmpC phenotype. J Antimicrob Chemother 2010;65:460-4.

[15] Peter-Getzlaff S, Polsfuss S, Poledica M, Hombach M, Giger J, Böttger EC, et al. Detection of AmpC $\beta$-lactamase in Escherichia coli: comparison of three phenotypic confirmation assays and genetic analysis. J Clin Microbiol 2011;49: 2924-32.

[16] Haldorsen B, Aasnaes B, Dahl KH, Hanssen AM, Simonsen GS, Walsh TR, et al. The AmpC phenotype in Norwegian clinical isolates of Escherichia coli is associated with an acquired ISEcP1-like ampC element or hyperproduction of the endogenous AmpC. J Antimicrob Chemother 2008;62:694-702.

[17] Muratani T, Kobayashi T, Matumoto T. Emergence and prevalence of $\beta$-lactamase-producing Klebsiella pneumoniae resistant to cephems in Japan. Int J Antimicrob Agents 2006;27:491-9.

[18] Yan JJ, Ko WC, Wu HM, Tsai SH, Chuang CL, Wu JJ. Complexity of Klebsiella pneumoniae isolates resistant to both cephamycins and extended-spectrum cephalosporins at a teaching hospital in Taiwan. J Clin Microbiol 2004;42: 5337-40.

[19] Singtohin S, Chanawong A, Lulitanond A, Sribenjalux P, Auncharoen A, Kaewkes W, et al. CMY-2, CMY-8b, and DHA-1 plasmid-mediated AmpC $\beta$-lactamases among clinical isolates of Escherichia coli and Klebsiella pneumoniae from a university hospital, Thailand. Diagn Microbiol Infect Dis 2010;68:271-7.

[20] Hussain M, Hasan F, Shah AA, Hameed A, Jung M, Rayamajhi N, et al. Prevalence of class A and AmpC $\beta$-lactamases in clinical Escherichia coli isolates from Pakistan Institute of Medical Science, Islamabad, Pakistan. Jpn J Infect Dis 2011:64:249-52

[21] Iabadene $H$, Messai Y, Ammari H, Alouache S, Verdet C, Bakour R, et al. Prevalence of plasmid-mediated AmpC $\beta$-lactamases among Enterobacteriaceae in Algiers hospitals. Int J Antimicrob Agents 2009;34:340-2.

[22] Corvec S, Crémet L, Leprince C, Dauvergne S, Reynaud A, Lepelletier D, et al. Epidemiology of Escherichia coli clinical isolates producing AmpC plasmidic $\beta$ lactamase during a 5-year period in a French teaching hospital. Diagn Microbiol Infect Dis 2010;67:277-81.

[23] Girlich D, Naas T, Bellais S, Poirel L, Karim A, Nordmann P. Biochemical-genetic characterization and regulation of expression of an ACC-1-like chromosomeborne cephalosporinase from Hafnia alvei. Antimicrob Agents Chemother 2000;44:1470-8.

[24] Naseer U, Haldorsen B, Simonsen GS, Sundsfjord A. Sporadic occurrence of CMY-2-producing multidrug-resistant Escherichia coli of ST-complexes 38 and 448, and ST131 in Norway. Clin Microbiol Infect 2010;16:171-8.

[25] Oteo J, Cercenado E, Cuevas O, Bautista V, Delgado-Iribarren A, Orden B, et al. AmpC $\beta$-lactamases in Escherichia coli: emergence of CMY-2-producing virulent phylogroup D isolates belonging mainly to STs $57,115,354,393$, and 420 and phylogroup B2 isolates belonging to the international clone O25b-ST131. Diagn Microbiol Infect Dis 2010;67:270-6.

[26] Fakhr MK, Nolan LK, Logue CM. Multilocus sequence typing lacks the discriminatory ability of pulsed-field gel electrophoresis for typing Salmonella enterica serovar Typhimurium. J Clin Microbiol 2005;43:2215-9.

[27] Johnson JK, Arduino SM, Stine OC, Johnson JA, Harris AD. Multilocus sequence typing compared to pulsed-field gel electrophoresis for molecular typing of Pseudomonas aeruginosa. J Clin Microbiol 2007;45:3707-12.

[28] Noller A, McEllistrem M. Multilocus sequence typing reveals a lack of diversity among Escherichia coli 0157:H7 isolates that are distinct by pulsed-field gel electrophoresis. J Clin Microbiol 2003;41:675-9. 